\title{
Teatro Nucleo: Un teatro de exilio en exilio (de Buenos Aires a Ferrara)
}

\section{Q Claudia Andrea Cattaneo Clemente}

Pontificia Universidad Católica de Chile / Alma Mater Studiorum Università di Bologna, Italia cacattaneo@uc.cl

Fecha de recepción: 15/07/2020. Fecha de aceptación: 09/08/2020

\begin{abstract}
Resumen
Teatro Nucleo es un grupo teatral argentino-italiano que ha desarrollado su labor teatral a partir del exilio que experimentaron sus fundadores, lo que les impulsó a indagar en las consecuencias escénicas y humanas de los significados del exilio, como motor de múltiples relaciones identitarias y terapéuticas. Las características que este grupo teatral manifiesta en su trabajo lo sitúan dentro de las manifestaciones más relevantes de un teatro desplazado, poniendo en jaque la línea que históricamente ha dividido al teatro como arte y como terapia. Teatro Nucleo trabaja en los bordes del arte teatral performativo y asume el exilio como un gesto político que impulsa actos de conciencia en cada espectador.
\end{abstract}

Palabras clave: Teatro Nucleo, exilio, laboratorio, política, Czertok.

\section{Teatro Nucleo: A Theater of Exile in Exile (from Buenos Aires to Ferrara)}

\begin{abstract}
Teatro Nucleo is an Argentine-Italian theatre group that has developed its theatrical work on the basis the exile experienced by its founders, which prompted them to investigate the scenic and human consequences of exile and motivated multiple identity and therapeutic relationships. The characteristics of the group's work place it within the most relevant manifestations of a displaced theater, questioning the line that has historically divided theatre as art and as therapy. Teatro Nucleo works on the edges of performative theatrical art and assumes exile as a political act that promotes acts of conscience in each viewer.
\end{abstract}




\section{Introducción ${ }^{1}$}

El grupo teatral Teatro Nucleo, de Ferrara (Italia), posee una larga trayectoria. Fundado en 1974 en Buenos Aires por los actores Horacio Czertok y Cora Herrendorf, inicia su trabajo escénico en la Compañía teatral y política Comuna Baires, una comunidad teatral independiente argentina, fundada por Renzo Casali (fallecido el 9 de abril de 2010 en Milán), Liliana Duca, Coco Leonardi y Antonio Llopis, el 5 de mayo de 1969 en la Cortada de San Lorenzo, San Telmo, Buenos Aires, bajo el alero del Centro dramático Buenos Aires-Teatro Laboratorio.

Renzo Casali fue cofundador del "Centro Dramático Buenos Aires - Teatro Laboratorio" - luego denominado grupo teatral Comuna Baires - (1969) y de la Escuela Europea de Teatro y Cine (1977) y de Willaldea Green Village - il Villaggio del Teatro (1984). Como actor, dramaturgo y director teatral ha presentado espectáculos en los más importantes festivales internacionales. Trabajó en el cine como guionista, actor y director. Autor de textos teóricos sobre el teatro, la escritura y la dirección cinematográfica, ha trabajado en los Estados Unidos, Cuba, Argentina, Italia, España y Suecia. Hasta su fallecimiento en 2010 dirigió la Comuna Baires Agora Club de Milán. (Famá Hernández, 2012: en línea)

Fue el primer grupo teatral en Argentina en desarrollar su trabajo actoral bajo la premisa del laboratorio y en producir textos de análisis, crítica y dramaturgia teatral, publicados en la revista autogestionada Teatro 70 (también llamada Comuna 70 y Cine 70), que saca a la luz su primer número en 1970.

El grupo trabajaba intensamente las situaciones límites poniendo el acento en la violencia emotiva, se pretendía con ello obligar al espectador a lo que denominaron: "identificación irracional con lo que está ocurriendo delante de sus ojos" Así, cuando el espectador intenta una explicación racional de lo que está sucediendo y de aquello que le está sucediendo a él como espectador, ya es tarde y entra en un torbellino donde se violenta la psiquis, el cuerpo y la moral y ya no es, entonces, solamente un tema teatral, sino una interpelación a cada espectador, un interrogante que sólo cada uno puede responderse. (Famá Hernández, 2012: en linea. El énfasis es del autor)

A este grupo pertenecieron Horacio Czertok y Cora Herrendorf antes de partir al exilio y radicarse en Ferrara, fundando la compañía estable Teatro Nucleo. Comuna Baires continúa trabajando en Milán hasta nuestros días.

Horacio Czertok nace en Comodoro Rivadavia, en la Patagonia argentina. en 1947. Mientras estudia electrónica, se acerca al teatro que sentía como una herramienta para la transformación social. A los 19 años, crea su primer grupo teatral en su ciudad natal, debutando formalmente con Juegos 1 (1969). Dos años después, en el Centro Dramático Buenos Aires (creado por Comuna Baires de Casali, Duca, Leonardi y Llopis), inicia su investigación que posteriormente continuará en exilio. En dicho Centro conoce la metodología de laboratorio teatral, "el teatro como un laboratorio para una vida nueva, dedicado a una ética que quería como centro focal de la existencia humana el arte, a lo cual todo era consagrado" (Czertok,

1 La bibliografía principal que orienta este estudio de la compañía Teatro Nucleo es el libro escrito por Horacio Czertok, "Teatro in esilio: appunti e riflessioni sul lavoro del Teatro Nucleo" (2010, ediciones Teatro Nucleo, 3ª. edición), en donde se expone un estudio de Ferdinando Taviani (“Il teatro è l'arte di lottare”), un prefacio de Gerd Koch, (Universidad de Berlín) y una intervención teórica de Manuela Rosetti (“Materiali per una storia del Teatro Nucleo"). La segunda edición (año desconocido) pertenece a Editoria e Spettacolo. La primera edición (1999), perteneciente a Bulzoni editore (Roma), fue revisada y ampliada con los comentarios analíticos de Daniele Seragnoli y Barbara Di Pascale. Estos estudiosos han escrito otro excelente artículo: "Il gabbiano di Anton Cechov. Punti di vista e primi piani su una creazione di Teatro Nucleo", 1996, Teatro comunal de Ferrara. La edición que utilizo para este ensayo es la tercera. 
2010: 229)[Traducción libre de: "il teatro come un laboratorio per una vita nuova, allinsegna di un'etica che voleva come centro focale della esistenza umana l'arte, cui tutto era consacrato"]

En el mismo Centro, conoce a la joven actriz Cora Herrendorf, con quien se casará y tendrá dos hijos, Natasha (actual co-directora del Teatro Nucleo) y Max. Juntos formarán una extensión del grupo teatral Comuna Baires en 1974. En febrero del mismo año, Horacio Czertok es secuestrado y torturado por un comando armado de las Fuerzas Tres A (Alianza Anticomunista Argentina), siendo amenazado con su inminente asesinato y el de todo su grupo teatral si no abandonaba el país. Este hecho determina la salida del grupo Comuna Baires hacia Italia (Milán), permaneciendo solo Czertok y Herrendorf en Argentina para formar el grupo teatral Nucleo y la revista Cultura. Ante la urgencia política que vivía el país, Teatro Nucleo se dedicó a crear una serie de proyectos interdisciplinarios con claros objetivos sociales, siempre manteniendo el trabajo de laboratorio del arte y del actor. Consideraba que la mayor necesidad era la ayuda terapéutica de los que estaban siendo recluidos y torturados y de pacientes tóxico-dependientes. Así, iniciaron talleres con operarios sanitarios y comenzaron la divulgación de las investigaciones que realizaban, a través de la revista Cultura, cuyo primer número sale en junio de 1974, alcanzando a publicar ocho números en total hasta 1978. En la revista publican sus primeros manifiestos, donde declaran sus objetivos como compañía teatral social:

Nucleo es un teatro mental, no un lugar topográfico, donde algunas personas pueden vivir de acuerdo con las propias ideas sobre la vida. El grupo tiene diversos rostros, en cuanto presenta espectáculos de varias tipologías, produce proyectos interdisciplinarios con impacto sociológico y cultural, crea situaciones pedagógicas. Se compromete en crear relaciones con las instituciones públicas y privadas, para realizar programas comunes sobre enfermedades de origen sociocultural o toxicodependencias. (...). (Czertok, 2010: 230) [Traducción libre de: “Nucleo è un teatro mentale, non un luogo topografico, dove alcune persone possono vivere d'accordo con le proprie idee sulla vita. Il gruppo ha diversi volti, in quanto presenta spettacoli di varia tipologia, produce progetti interdisciplinari con impatto sociologico e culturale, crea situazioni pedagogiche. Si impegna in rapporti con istituzioni pubbliche e private, per realizzare programmi comuni riguardanti le malattie di origine socioculturale $o$ le tossicodipendenze. (...)"]

El grupo gozaba de cierta independencia económica gracias a la venta de la revista, lo que les permitía libertad de escoger proyectos y lugares y les aseguraba un público fiel que compraba la revista. Esto se vio interrumpido con el golpe de Estado argentino de 1976. En 1975, Teatro Nucleo crea su primer espectáculo Herodes, un espectáculo sobre la tortura que, un año antes del golpe de Estado, ya se podía evidenciar en el país. Este espectáculo los conduce a diversos festivales y encuentros en Italia y Europa, marcando un antes y un después para la compañía, que por entonces se encontraba trabajando con un objetivo político claro: la denuncia de lo que estaba ocurriendo en Argentina y que era totalmente desconocido para el resto del mundo.

El grupo estaba impregnado de la fe en las posibilidades de la acción cultural como una condición indispensable para crear una nueva conciencia de la realidad social. Ya en ese momento había cierta falta de confianza en la posibilidad de generar cambios políticos significativos, a través de la acción política tradicional. Por lo tanto, la acción del grupo también se dirigió a los políticos militantes tradicionales. Sin embargo, no éramos un "grupo de izquierda": simplemente queríamos hacer un teatro donde el trabajo del maestro fuera lo más importante. Habíamos leído Grotowski, habíamos leído las experiencias del Living Theater. Eran muy importantes para nosotros, como iluminaciones. (Czertok, 1985: en línea) 
[Traducción libre de: "Il gruppo era pervaso dalla fede nelle possibilità dell'azione culturale qualle condizione indispensabile per creare una nuova coscienza della realtà sociale. Già in quel periodo si nutriva una certa sfiducia nella possibilità di generare cambiamenti politici significativi, attraverso l'azione politica tradizionalmente intesa. Così, l'agire del gruppo si rivolgeva anche ai militanti politici tradizionali. Eppure non eravamo un 'gruppo di sinistra': volevamo semplicemente fare un teatro dove il lavoro dell'attore fosse la cosa più importante. Avevamo letto Grotowski, avevamo letto le esperienze del Living Theatre. Sono state molto importante per noi, come illuminazioni."]

Con Herodes, el grupo teatral se introduce en el margen, en el descentramiento teatral, que implicaba abandonar los espacios tradicionales e institucionales para presentarse en plazas, fábricas, espacios abandonados, escuelas, carpas, bodegas, entre otros. Este hecho causó un enorme impacto en Italia entre los críticos y estudiosos del teatro, ya que advertían un importante cambio histórico en la forma de concebir el teatro. Es el espectáculo el que va a los espectadores; los encuentra allí donde viven, donde realizan sus compras, donde se recrean o pasean a sus mascotas. Sin embargo, la obra convulsionó al público italiano por la enorme violencia puesta en escena y sobre los cuerpos. Los críticos la consideraron fuera de los gustos del público italiano, habituado a un teatro más bien clásico. Sin embargo, fue tal el impacto de su representación, que la Rai TV documentó completamente el espectáculo e inició un debate sobre la validez del uso de la violencia para denunciar la violencia.

En marzo de 1976, mientras el grupo se encontraba aun en gira por Italia, el Golpe de Estado en Argentina obligó a Teatro Nucleo a permanecer en Europa. La Municipalidad de Ferrara les ofreció un espacio para continuar con su trabajo teatral y de laboratorio, siempre ligado a la sanación social y política por medio del arte escénico.

En 1977, Teatro Nucleo propone al hospital psiquiátrico Rizzeddu di Sassari un programa de laboratorios con operadores sanitarios y un proyecto de animación con pacientes. El objetivo consistía en iniciar una relación natural y más cercana entre la ciudadanía y los pacientes del hospital psiquiátrico a través de la fiesta, adhiriendo a la nueva tendencia internacional que regía los centros de internación psiquiátricos (manicomios). "¿Por qué el domingo no vienes a jugar entre locos?" (Czertok, 2010: 233)[Traducción libre de: "Perché domenica non vieni a giocare fra i matti?"] era la invitación que Teatro Nucleo extendía a los ciudadanos. Durante estas intervenciones, conocen al doctor Antonio Slavich, por entonces director del Hospital psiquiátrico de Ferrara, quien les propone organizar un laboratorio en su hospital. Desde aquel momento, se convertirán en los portavoces de las nuevas políticas de apertura de los manicomios que promovía la Psiquiatría Democrática y que se concretría con la ley 180. En efecto, dicha ley fue impulsada por el psiquiatra italiano Franco Basaglia, considerado el psiquiatra más importante de Italia por su perspectiva antipsiquiátrica de la medicina de aquellos años. La ley fue aprobada en mayo de 1978 y en ella se prohíbe en Italia la internación de pacientes psiquiátricos en contra de su voluntad (pudiendo incluso aceptar o rechazar tratamientos propuestos) y obliga a mantener condiciones sanitarias adecuadas y un tratamiento humano a aquellos que se encuentran internados. Es una ley sobre los derechos de los pacientes psiquiátricos, que instó a eliminar paulatinamente los manicomios para incorporar salas psiquiátricas especiales dentro de los hospitales generales. Basaglia fue el fundador del grupo sanitario y político de izquierda, Psiquiatría Democrática, que mantuvo estrecha relación con artistas plásticos como Vittorio Basaglia (primo del médico) y artistas teatrales como Horacio Czertok para hacer del arte, el vehículo del cambio que la ley 180 instaba a realizar.

De esta experiencia nace el primer espectáculo de calle de Teatro Nucleo, en 1978, y los ferrareses pudieron presenciar Luci. En una entrevista con Horacio Czertok 
en agosto de 2017 (b), me comenta que han escogido las calles y plazas, porque al llegar a Italia se dieron cuenta de que las escenografías teatrales no alcanzaban la grandeza de aquellas que se enmarcaban en la belleza de las ciudades, con monumentos y edificios antiguos, llenos de historia y poco visibilizados por los habitantes de Europa, habituados a verlas siempre. La idea, comenta Czertok, era darles un nuevo propósito y llenar aquellos espacios de nuevas historias. El espectáculo se iniciaba con una parada al estilo del Odin Teatret, con quienes Teatro Nucleo habían entablado una relación cercana de colaboración artística, iniciada años antes en Argentina.

Luego de este primer espectáculo y gracias al suceso que produjo en la comunidad ferrarese y en la propia comunidad psiquiátrica, en enero de 1978 se realiza el convenio "La scopa meravigliosa" (La escoba maravillosa), haciendo alusión a la necesidad de barrer el polvo de ideas obsoletas sobre los pacientes psiquiátricos y las terapias crueles e inhumanas que se llevaban a cabo antes de la ley 180.

En los meses siguientes, el grupo logra volver a Argentina, participando, a su vez, en el famoso y decisivo encuentro inter-Latinoamericano de Ayacucho (Perú) con el que Eugenio Barba logra instaurar la significación de los grupos teatrales como un tercer teatro. La compañía pensaba permanecer en Argentina para realizar un trabajo teatral de resistencia a la dictadura; sin embargo, el inminente peligro de muerte que se cernía sobre los miembros del grupo, los hace abandonar la idea y regresar a Italia para quedarse allí definitivamente.

En Ferrara, el grupo no solo continuó su trabajo con el hospital psiquiátrico, sino con proyectos pedagógicos en escuelas, barrios marginales, hospitales de niños y jóvenes, entre otros, que le permitieron sostenerse económicamente y realizar laboratorios de investigación teatral con los propios actores de la compañía,que ahora contaba con jóvenes italianos entre sus integrantes. En el laboratorio, se realizaba una búsqueda actoral que profundizaba el método Stanislavski para encontrar en él las aristas que aún no se habían descubierto. Czertok se refiere a Stanislavski como el único método de actuación que existe, puesto que todos los demás métodos se refieren a la puesta en escena y no a los mecanismos internos y externos que rigen el trabajo actoral. (2017: entrevista).

Para Czertok, el exilio no posee connotaciones negativas; es más, le ha incitado a crear proyectos que no habría tenido la urgencia de generar en su propio país. Asumiendo esta concepción de exilio, podemos ver que el trabajo de Czertok se desenvuelve dentro de significados que pertenecen al exilio sin tocar directamente el tema o el concepto mismo. Cuando Czertok habla de su teatro de exilio, lo hace refiriéndose a las circunstancias que originaron su permanencia en Italia, no a un teatro que es atravesado por el exilio desde sus cimientos. Teatro Nucleo no cambia los objetivos que lo condujeron a fundarse como grupo social y político Comuna Baires; es más, en exilio, profundizan dichos objetivos dedicándose al trabajo terapéutico como lo hicieran en Argentina.

Czertok se ve sacudido profundamente con el exilio sufrido, lo que lo lleva a cambiar la óptica con la que enfrenta sus objetivos como actor (aunque continúan siendo sociales) y como creador. Su obra se vuelve más comunitaria con elementos autobiográficos; comienza a investigar los quiebres que el exilio provoca en los seres humanos y cómo esto interfiere en la creación teatral y en los signos de la escena espectacular. En una entrevista realizada a Czertok (Ferrara, 2017), éste comenta que para él y su compañía, si bien el exilio fue una situación dolorosa, también les dio la posibilidad de desarrollar su trabajo en Italia, sin experimentarlo como una tragedia. 


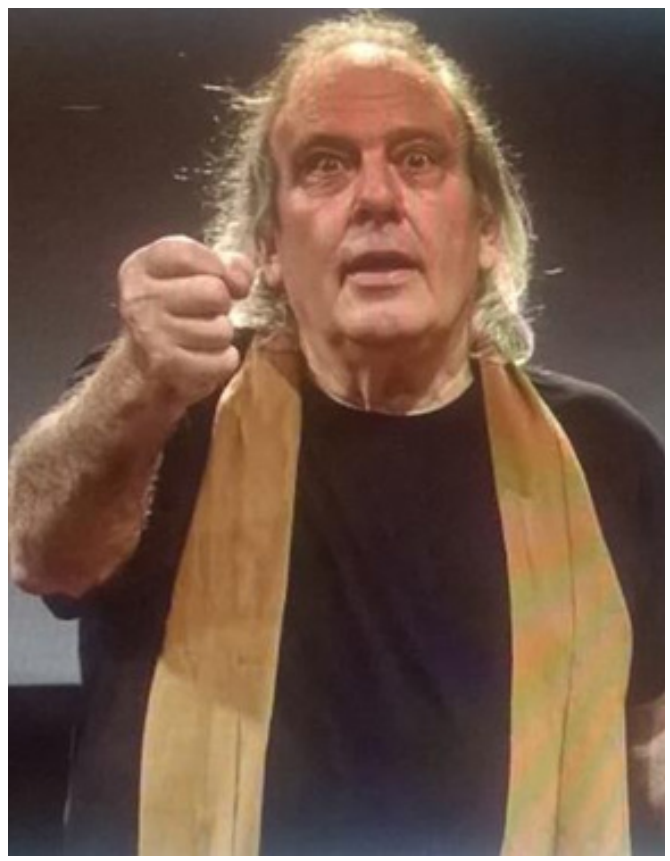

Horacio Czertok, co-creador y director del Teatro Nucleo de Ferrara. Teatro en/de exilio. Fotografía de Paolo F. Peloso. - Fuente: http://www.teatronucleo.org/

En 1979, Czertok conoce a Marco Tani, asesor de cultura de Copparo, una municipalidad cercana a Ferrara. A partir de este encuentro, nace la idea de realizar un festival anual de verano en Copparo llamado "Encuentro de teatro de grupo", en donde se invadían las calles del municipio con actores en murga para hacer presente el sentido antropológico del teatro como fiesta de participación, siguiendo a Eugenio Barba en sus preceptos del teatro antropológico de trueques culturales.

¿Cuál es la utilidad cultural y social del teatro hoy? Es este el total sentido de la experimentación teatral: encontrar la real especificidad del instrumento mismo. Transformar un ritual cultural en una ceremonia sensata. Dar al hecho de 'ir al teatro' y 'ser en el teatro' una función precisa, un baño espiritual que solamente el teatro, por su condición de 'hic et nunc', puede dar. Por esto, es necesario salir de la lógica de la compañía en gira que la antigua legislación del Estado continua a imponer para subvencionar el teatro. (...) Pero entre tanto, el teatro está ligado a la industria del entretenimiento, (...) Nuestra 'entertainmemnt industry' a nivel teatral no funciona sin la pesante intervención del Estado. (...) Existe un teatro que se hace menos de convenciones y de la maquinaria escénica más cara. (...) Si los descubrimientos, los desarrollos en el mundo del teatro de los últimos años nos demuestran que el teatro no existe, que existen, en su lugar, tantos Teatros portadores de valores y tradiciones, ¿por qué obstinarse en ver solamente en una dirección y obligar a los demás a ver esa parte? (Czertok, 1982. Cit. En: 2010: 236)

[Traducción libre de: "Qual è l'utilità culturale e sociale del teatro oggi? È questo tutto il senso della sperimentazione teatrale: trovare la reale specificità dello strumento stesso. Trasformare un rituale culturale in una cerimonia sensata. Dare al fatto di 'andare a teatro' ed 'essere a teatro' una funzione precisa, un bagno spirituale che soltanto il teatro per la sua condizione di 'hic et nunc' può dare. Per questo è necessario uscire dalla logica della compagnia di giro che l'antica legislazione dello Stato continua ad imporre per sovvenzionare il Teatro (...) Ma intanto il teatro è legato all'industria dell'intrattenimento, (...) La nostra éntertainment industry' a livello teatrale non funziona senza il pesante intervento dello Stato. (...) Esiste un teatro che fa a meno tanto 
delle convenzioni quanto del costosissimo macchinario scenico. (...) Se le scoperte, gli sviluppi nel mondo del teatro negli ultimi anni ci dimostrano che il teatro non esiste, che esistono invece tanti Teatri portatori anch'essi di valori e tradizioni, perché ostinarsi a guardare soltanto in una direzione ed obbligare gli altri a guardare da quella parte?"]

Esta propuesta no fue bien recibida por los grupos teatrales tradicionales que trabajaban en la región, pues implicaba reducir sus subvenciones para dividirlas con otros grupos más pequeños y experimentales, hecho que, finalmente, provocó la suspensión del festival en 1982.

Sin rendirse en su objetivo de hacer del teatro un instrumento de cambio social, Teatro Nucleo continuó su labor teatral con el montaje de otros espectáculos como: Ifunesti (1980), Eresia (1981), Sogno di una cosa (1982). En 1983, la compañía inicia una gira por Europa que dura hasta inicios de 1985, año en que la Casa de la Cultura de Orléans le encomienda a la compañía crear un espectáculo que involucre a toda la ciudad. El resultado es Operazione Fahrenheit, un agit-prop de calle inspirado en la novela de Bradbury. El espectáculo creaba un juego de confusión entre realidad y ficción, en donde los actores de la compañía junto a algunos grupos de actores-ciudadanos comienzan a crear escuadras militarizadas para secuestrar todos los libros de la ciudad y quemarlos en la plaza principal. Lo interesante de esta puesta en escena fue su sentido de experimento social, que dio como resultado la creación espontánea de comandos, improvisados por personas que no estaban al tanto del juego, para rescatar los libros y esconderlos y de comandos de personas que entregaban voluntariamente sus libros y delataban a sus vecinos que aun los tenían en sus casas. Esta obra fue replicada en diversas ciudades de Europa, añadiendo algunos elementos que se acercaban a las características culturales particulares de cada lugar.

En 1986, la compañía retorna a Ferrara, esta vez, sin sede estable, ya que el municipio había declarado lugar inhabitable la antigua sede del centro de la ciudad. Realizando los ensayos en distintos lugares provisorios, la compañía logra montar Rosa in ottobre (sobre la escritora alemana Rosa Luxemburg) que trataba sobre la participación de la mujer artista en la política.

Uno de los proyectos más importantes de la compañía es Caravana Mir (MirCaravane, 1989)[Mir es una palabra rusa que tiene un doble significado: paz y villa], proyecto internacional enmarcado en el bicentenario de la revolución francesa. El proyecto consistía en una gran caravana teatral formada por más de doscientos actores y grupos que marchaban desde Moscú hasta París por seis meses (visitando cada ciudad en su camino y compartiendo espectáculos con los grupos locales). Al final del camino, el proyecto realiza un espectáculo colectivo llamado Odissea '89.

Ya en 1989, cuando la compañía regresa a Ferrara, logran mudarse a una sede estable que aun los alberga, un ex cine a las afueras de la ciudad, en Pontelagoscuro. Durante los años 90, la compañía cobra vital importancia en el contexto teatral italiano y europeo, siendo invitados a diversos festivales y encuentros en Alemania, Francia, España, entre otros.

La itinerancia ha marcado el trabajo de la compañía, considerada un grupo nómade de nuevos comediantes (a la antigua usanza de la Comedia del Arte italiana). Como bien declara Czertok

El espacio del teatro se abre, experimenta su propio modo de ser, de presentarse, de vivir el arte más allá de las convenciones espaciales. Un teatro que se declara nómade, en busca de un espectador propio entre la gente de la calle, de las plazas. Un espectador que escoge inesperadamente ser tal, desde el momento del 
encuentro con el teatro.

[Traducción libre de: "Lo spazio del teatro si apre, sperimenta il suo modo di essere, di presentarsi, di vivere l'arte al di la delle convenzioni spaziali. Un teatro che si afferma nomade, in cerca di un proprio spettatore tra la gente delle strade, delle piazze. Uno spettatore che sceglie inaspettatamente di essere tale dal momento dell'incontro con il teatro."] (2010: 243)

En 1999, Teatro Nucleo retorna a Argentina con Tempesta, espectáculo inspirado en la Shoah y en la rebelión del Ghetto de Varsovia, presentado entre 1997 y 1998 en el ex-campo de concentración de Dachau para la conmemoración de la noche de los cristales rotos, en el que Czertok y la directora Herrendorf incorporan la reflexión sobre el rol de la memoria y el testimonio en la sociedad contemporánea. Cabe señalar los orígenes hebreos de Czertok, por lo que este espectáculo, según sus propias palabras (2017), constituía una deuda que debía pagar. Un año después, esta vez en Buenos Aires (en una cancha de fútbol del Parque Chacabuco), en el marco de una memoria diversa como la de la dictadura militar y de los crímenes cometidos durante el régimen, la obra cobra resonancia nacional, siendo apreciado el trabajo del grupo durante los veinte años de exilio. En aquella ocasión, se les acerca un joven actor que les pregunta si ese Horacio Czertok es el mismo que había publicado dos décadas atrás una revista teatral llamada Cultura. Al enterarse que era el mismo, les cuenta que su propio grupo de teatro, hacia el final de la dictadura, buscaba un lugar donde hacer teatro de resistencia y que por casualidad (aunque es evidente que las casualidades no existen), se topan con una carpa abandonada donde encuentran unas cajas con documentos y libros, entre ellos, la revista teatral Cultura. Deciden que es un signo que les estaba mostrando su nuevo espacio de creación. Contactan al dueño que les autoriza a utilizar la carpa y comienzan a estudiar la revista y a preparar laboratorios teatrales para la creación. Como este grupo, existen muchos otros que, inspirados por los teatros de resistencia, comenzaron a llevar a escena obras que denuncian a los genocidas y torturadores de la dictadura que permanecen aun impunes. Desde la performance, cabe señalar al GAC (Grupo de Arte Callejero), que se formó en 1997 en Buenos Aires, cuando un grupo de estudiantes de Bellas Artes se reunió para realizar intervenciones de denuncia. En 1998 comienzan a participar en los escraches (que significa: arrojar algo con fuerza, es un nuevo tipo de performance guerrilla que devela la ubicación de perpetradores de atrocidades) de la agrupación H.I.J.O.S., donde "van señalando la distancia ("faltan 500 metros, 300 metros, 100 metros"), a la casa del torturador. El grupo grande de unas trescientas personas se aproxima a la casa del torturador. La policía los espera. Allí inician el rito de marcar el delito y declarar públicamente los crímenes que no han sido castigados legalmente. Pintan la acusación en la calle y en la acera. O la gritan. En casi todos los casos, los criminales señalan que no están. Apagan las luces y se van." (Taylor, 2014: en línea)- Este fue el primer retorno de la compañía al país de origen; sin embargo, su sede estable continúa siendo el Teatro Julio Cortazar de Pontelagoscuro, Ferrara.

En los siguientes puntos voy a enfocarme en resolver cuáles son las características del exilio presentes en las creaciones de Teatro Nucleo, empezando por conocer el especial punto de vista que su creador tiene sobre el teatro como herramienta política que trasciende los hechos particulares del exilio mismo. Seguiré con el método de laboratorio que es una característica importante en el teatro de exilio o del desplazamiento. Para terminar, revisaré la concepción de escenografía desplazada que se sitúa en el límite con la instalación. Teatro Nucleo descubre que el exilio les ha permitido abolir las distancias prejuiciosas del teatro de arte con el teatro de terapia. 


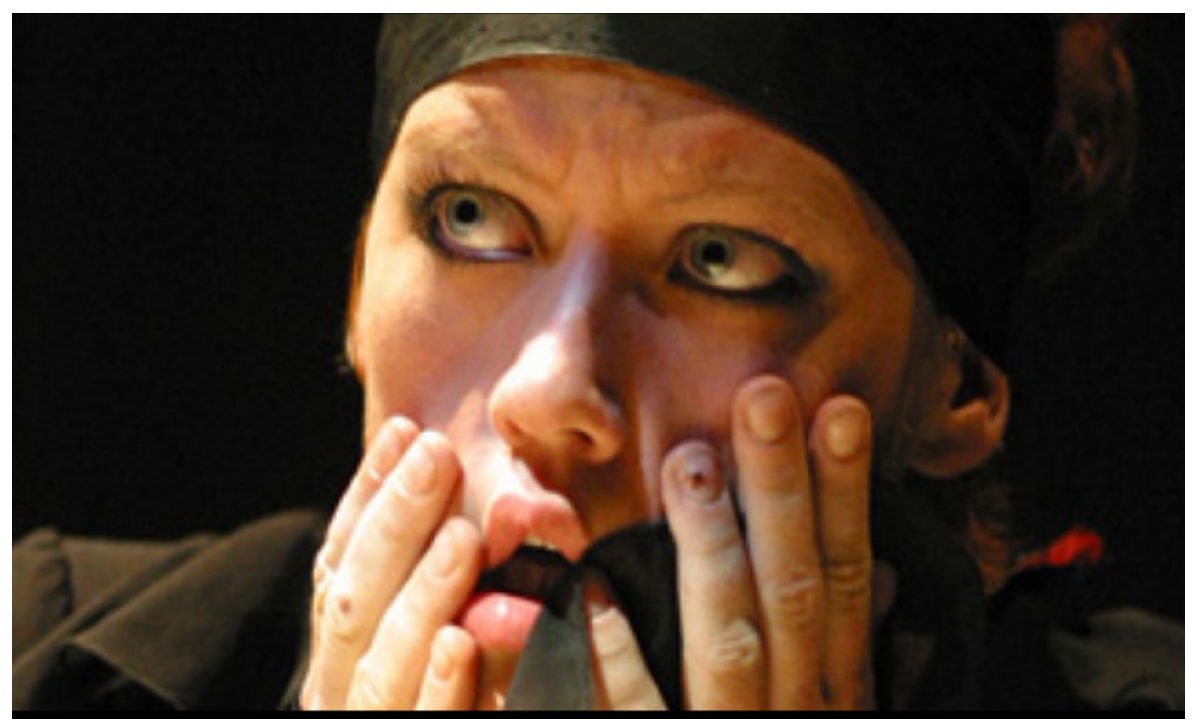

La actriz y directora teatral Cora Herrendorf en Hamlet (2004). Co-fundadora del Teatro Nucleo. Fuente: http://www.teatronucleo.org/

\section{Una propuesta de política teatral basada en el exilio}

Si bien Teatro Nucleo declara no ser un grupo de izquierda, es evidente la colaboración con la organización Psiquiatría Democrática creada por Basaglia y su visión del teatro como herramienta de cambio social que los acerca a un pensamiento de izquierda no militante. A su vez, como comenta Taviani, no se debe olvidar que

Comuna Baires no era un simple grupo teatral, era más bien un enclave determinado a llevar a cabo los valores de una sociedad basada sobre los principios del marxismo-Leninismo, luchando contra las huellas de la cultura 'burguesa', primero que nada desde su interior, eliminando la propiedad privada y afectando también las relaciones interpersonales. (Taviani. En: Czertok, 2010: 16)

[Traducción libre de: "Comuna Baires non era un semplice gruppo teatrale, ma un'enclave determinata realizzare i valori di una società basata sui principi del marxismo-leninismo, lottando contro le tracce della cultura 'borghese' innanzi tutto al suo interno, eliminando la proprietà privata e incidendo anche nei rapporti interpersonali."]

Sin embargo, Teatro Nucleo le otorga al concepto de política un renovado sentido dentro de los términos de Rancière, para quien la política no es el proceso de gobernar, como se concibe tradicionalmente, sino el acto de un sujeto que interrumpe ese proceso o, como comenta Etchegaray, "la política es definida como desacuerdo, como lucha, contra las teorías clásicas y modernas que la entienden como contrato, como consenso o como defensa de los derechos." (2014: 25). De esta manera, el filósofo argelino invierte el problema planteado por Foucault, que se preguntó por qué los hombres desean someterse al poder. Para Rancière, en cambio, lo importante es saber cuándo los hombres no se someten al poder, qué los impulsa a luchar por la libertad y la justicia, en contra de los sistemas políticos establecidos. Así, ha propuesto que la función de la política es la de servir de medio para que los recursos de una sociedad sean distribuidos de la forma más justa posible.

La política es la actividad que tiene por principio la igualdad y el principio de la igualdad se transforma en distribución de las partes de la comunidad en el 
modo de un aprieto [aporía]: ¿de qué cosas hay y no hay igualdad entre cuáles y cuáles? ¿Qué son esas qué, quiénes son esas ‘cuáles? ¿Cómo es que la igualdad consiste en igualdad y desigualdad? Tal es el aprieto propio de la política por el cual ésta se convierte en un aprieto [aporía] para la filosofía, un objeto de la filosofía. (...) La política existe cuando el orden natural de la dominación es interrumpido por la institución de una parte de los que no tienen parte. Esta institución es el todo de la política como forma específica del vínculo. La misma define lo común de la comunidad como comunidad política, es decir dividida, fundada sobre la distorsión que escapa a la aritmética de los intercambios y las reparaciones. (Rancière, 1996: 7-8, 25)

En este sentido, la política es el centro de la investigación teatral de Teatro Nucleo, al concebir las instituciones como un medio del cual es posible prescindir o utilizar, siempre que no se traicionen los objetivos esenciales de la creación, en pos de un bienestar común del ser humano. Czertok concibe el teatro como fiesta comunitaria, como acción de ser en una verdad que se encuentra de común acuerdo y que va a estar siempre en movimiento, mutando según mutan los actores, espectadores y situaciones escénicas. El teatro debe crear fiesta y exilio, sin embargo,

Con la palabra exilio se quiere definir no solo las condiciones en las que nos encontramos a causa del golpe de Estado de los generales argentinos. El teatro en sí tiende a ser un exilio del mundo, y nuestro teatro de los espacios abiertos es un voluntario exilio de los edificios teatrales, en el intento por reencontrar el mundo perdido del teatro. Teatro en exilio, finalmente, también del espectáculo, cuando se encuentra un sentido de necesidad en los lugares donde se manifiestan los seres humanos en crisis. (Czertok, 2010: 32)

[Traducción libre de: "Con la parola esilio si vuole definire non solo la condizione in cui ci siamo trovati a causa del colpo di Stato dei generali argentini. Il teatro in sé tende ad essere un esilio dal mondo, e il nostro teatro degli spazi aperti è un volontario esilio dagli edifici teatrali, nell'intento di ritrovare il mondo perduto dal teatro. Teatro in esilio, infine, anche dallo spettacolo, quando trova un senso di necessità nei luoghi dove si manifestano degli esseri umani in crisi."]

Para Czertok, el exilio es aquel significado que viaja dentro del artista y del espectáculo, un estado de crisis permanente que empuja al creador a moverse constantemente, a encontrar nuevas formas, nuevos modos de relacionarse con los territorios y sus espectadores. El exilio se halla dentro del teatro, es el teatro mismo. Es por ello que este teatro de exilio es un teatro autobiográfico, pues relata las historias personales del sentir del artista y de su exilio perenne por el arte, un territorio sin fronteras que deambula en la liminalidad del hecho escénico. 


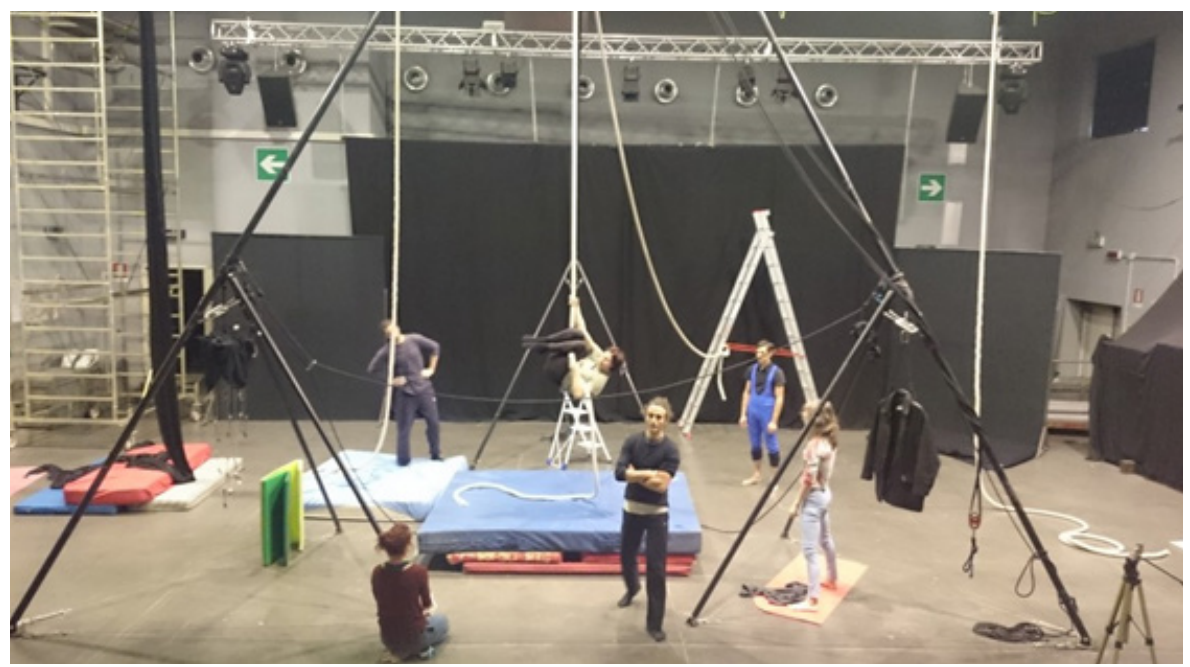

Los actores de Teatro Nucleo en entrenamiento dentro de la sala principal del espacio Teatro Julio Cortázar, Pontelagoscuro, Ferrara. - Fuente: http://www.teatronucleo.org/

Czertok trabaja en Italia con compañeros argentinos que habían sufrido la misma situación de exilio; sin embargo, los grupos militantes deseaban que se hiciera un teatro panfletario más que político; a su vez, la izquierda italiana comienza a criticar la violencia de los espectáculos de Czertok, especialmente aquel de 1977 donde exhibe en escena la tortura que él había experimentado en Argentina. Esto no es bien recibido por los compañeros de izquierda italianos que consideran que mostrar para impactar y no para denunciar es una violencia acrítica. "Entonces el exilio, para Horacio Czertok, fue doble: de la dictadura militar y la sordera política de los camaradas europeos" (Taviani. En: Czertok, 2010: 18)[Traducción libre de: "Sicchél'esilio, per Horacio Czertok, era doppio: dalla dittatura militare en ella sordità politica dei compagni europei."]

No se trata solo de Czertok, sino de muchos otros artistas exiliados que deben enfrentarse con una realidad muy distinta de aquella originaria, pero también, de una ignorancia profunda de lo que ocurre en otras culturas y realidades, un cerrar las puertas a aquello que no se conoce y que se piensa de un modo estandarizado. Es el mismo pensamiento eurocéntrico de Colón cuando llega a América y traduce el italiano que los indígenas 'hablaban muy mal. Cuando Colón se lanza a la gran aventura de su vida y descubre América en 1492, se encuentra con un nuevo mundo que observa e interpreta bajo el pensamiento eurocéntrico de la Edad Media, por ende, no intenta encontrar verdades, sino, confirmar ciertas verdades que traía consigo, pues, “(...) su convicción es siempre anterior a la experiencia. (...) Cuando algún dato concreto no encajaba dentro de sus ideas preconcebidas, tendía a descalificar a sus informantes diciendo que eran personas salvajes." (Todorov, 1993: 20) Colón no percibe la lengua de los indios como diferente, entonces, comienza a tener con ellos diálogos imaginarios e incoherentes, corrigiendo palabras que cree que ellos pronuncian mal y que él cree conocer de la lengua nueva.

Este tipo de comportamiento puede entenderse bajo la mirada que Edward Said expone en su obra Orientalismo (1978) y que hace mención a la forma discursiva del historiador al relatar la cultura del Otro. Cuando lo hace - dice Said- es desde un lenguaje colonialista e imperialista y dentro de un sistema académico que supuestamente no tiene juicios de valor frente a la lengua, cultura o historia de las colonias; sin embargo, "Todo conocimiento académico (...) está teñido o violado por el burdo hecho político del colonialismo." (Said, 2013: 11). Esta visión posee, sin embargo, una ambivalencia, para Homi Bhabha (1994) y la ejemplifica muy claramente cuando ilustra la escena de un misionero tratando de enseñar a los indios de religión hindú, 
la comunión cristiana. Cuando el misionero explica que la comunión consiste en comer el cuerpo de Cristo y beber su sangre, los hindúes vegetarianos reaccionan horrorizados. Para Bhabha, en esta escena la cultura blanca inglesa es la que resulta traicionándose a sí misma, convirtiendo al misionero en un vampiro caníbal.

Un colonialismo que se esconde en los rechazos hacia una expresión que denuncia la violencia de la tortura que se estaba llevando a cabo en los países Latinoamericanos en dictadura. Para algunos ciudadanos de Europa, lejos de ser una denuncia, resulta ser una expresión de personas violentas de una cultura que no goza del pleno desarrollo del mundo civilizado. En pleno siglo XX (y me atrevo a decir, siglo XXI), aún quedan residuos de esta visión de mundo. De ella, se aprovechan las bandadas de xenófobos y nacionalistas extremos que pueblan nuestro mundo contemporáneo.

Para el teatro de exilio de Czertok, este pensamiento debe ser combatido con una filosofía del exilio que atraviese todos los ámbitos de la escena, partiendo por los espacios exiliados, es decir, fuera de su propio territorio (edificio teatral), pasando por los cuerpos de los actores que piensan la violencia como una forma de rebelión y de romper las fronteras del pensamiento eurocéntrico y partidario, y llegando a los temas escogidos para ser representados (o presentados). Czertok introduce la performance sin hacer alusión de este hecho en sus escritos o conferencias; sin embargo, es evidente que la performance está presente en todos sus espectáculos. Es una intromisión que cumple la función de incorporar los significados del exilio para abrir un tercer espacio de re-presentación.

Para ello, Teatro Nucleo se propone algunas palabras claves que no pueden ser separadas del teatro. Estas son: riesgo y desafío, pues, tal como Artaud incitaba a hacer, buscan la verdad escénica en las calles, donde estas palabras cobran un real y concreto significado para el actor y el espectador:

El público, incluso si siente verdadero lo que es falso, conoce el sentido de verdad y siempre responde cuando se le presenta. Hoy, sin embargo, ya no es en la escena donde debemos buscar la verdad, sino en la calle; Cuando a la multitud de las calles se le ofrece la oportunidad de mostrar su dignidad humana, se puede estar seguro de que ella lo mostrará. (Artaud. Cit. En: Czertok, 2010: 224)

[Traducción libre de: Il pubblico, anche se ritiene vero ciò che è falso, ha il senso del vero e risponde sempre quando glielo si presenta. Oggi però non è più sulla scena che dobbiamo cercare il vero, ma per istrada; quando alla folla delle strade si offre un'occasione di mostrare la sua dignità umana, si può star certi che essa la mostrerà.]

Haré aquí un paréntesis necesario para retornar a uno de los referentes de Czertok desde Comuna Baires hasta el actual Teatro Nucleo. Me refiero al trabajo del Living Theatre de Beck y Malina. Para este grupo, que en palabras de Valenti (2015) ha revolucionado el teatro al ligar su objetivo de alta calidad artística con su eficacia política en las sociedades de control, pues, el teatro debe aprovechar cada una de sus herramientas para crear experiencia con el espectador. En este sentido, el trabajo del actor debe valer la vida de cada uno de ellos, despertando y preparando las conciencias para la acción social:

Porque 'el uso de las palabras -decía Judith-puede convertirse no solo en un ejercicio lógico, sino en uno experiencial: podemos experimentar las palabras' y 'el teatro debe alcanzar esto, $y$ transformar los contenidos ideales y los poéticos en momentos de experiencia para nosotros y para el público participante'. (Malina. Cit. En: Valenti, 2015: en línea) 
[Traducción libre de: Perché ‘'uso delle parole - diceva Judith - può diventare un esercizio non solo logico, ma esperienziale: possiamo fare esperienza delle parole' e 'il teatro deve arrivare a questo, e trasformare i contenuti ideali e quelli poetici in momenti di esperienza per noi stessi e per il pubblico partecipante'.]

Para Valenti, el cambio que ha generado el Living es el que hoy percibimos como una vanguardia del teatro social, sin reconocer que ya Malina y Beck habían explorado estos rumbos desde el año 1947, se refiere a

La creación colectiva, el cuestionamiento de la autoridad del director, la centralidad y la responsabilidad del actor, el escape de los edificios tradicionales y la conquista de espacios alternativos, la demolición de la frontera entre actores y espectadores. (Valenti, 2015: en línea)

[Traducción libre de: "La creazione collettiva, la messa in discussione dell'autorità registica, la centralità e la responsabilità dell'attore, la fuoriuscita dagli edifici tradizionali e la conquista di spazi alternativi, l'abbattimento del confine fra attori e spettatori."]

Si bien estas características pertenecen a un teatro de exilio o del desplazamiento, los objetivos políticos (y la concepción de la misma) son muy diversos. Para el Living, el teatro debía ser un espacio que le hablara al espectador sobre aquellas injusticias sociales y políticas que experimentaba, lo invitaban a vivir la experiencia de pasar por el borde de la ilegalidad, de la revolución anárquica y pacifista, del panfleto político, que agitara las masas para revelarse con conciencia. Así, la distancia con el espectador era impensable, pues, para convencerlo de alzarse, debían generar el espacio de confiabilidad. Era un teatro para espectadores y no con espectadores, como el caso del teatro social y, puntualmente, el teatro de exilio. La lucha del Living era contra el centro desde la periferia; la lucha del teatro de exilio es con el centro y con la periferia, para transformarse en frontera.

El concepto de política ha cambiado desde los tiempos de Beck y Malina: los 50 y 60 fueron años de redefinición de la política debido a los conflictos que Estados Unidos había iniciado en el mundo. Giacché comenta:

La redefinición de la "política" parecía en ese momento la más incisiva y la más valiente: forjada con la contribución teórica de unos pocos pero verificada por la militancia de tantos, si no, de todos los estudiantes del movimiento (...) El anticonsumismo fue entonces el ideal básico que inspiró todas las ideologías cumbre: una revuelta paradójica contra uno mismo, contra la clase burguesa de pertenencia o aspiración, contra la abundancia y obsolescencia de los bienes e incluso contra las ventajas de la riqueza y los privilegios del poder ... Como se puede ver, una revolución completamente cultural, a la que uno se adhirió de verdad, y no tanto amando y no todos armados como hoy cuenta la Historia. (Giacché, 2013: en líinea)

[Traducción libre de: La ridefinizione della "politica" sembrò al momento la più incisiva e la più coraggiosa: forgiata con il contributo teorico di pochi ma verificata dalla militanza di tanti se non di tutti gli studenti del movimento (...) L'anticonsumismo era allora l'ideale di base che ispirava tutte le ideologie di vertice: una paradossale rivolta contro se stessi, contro la classe borghese di appartenenza o di aspirazione, contro l'abbondanza e l'obsolescenza delle merci e perfino contro i vantaggi della ricchezza e i privilegi del potere... Come si vede, una rivoluzione tutta culturale, alla quale si aderiva per davvero, e non tanto amati e non tutti armati come oggi racconta la Storia.]

Es esta redefinición de la política la que sentó las bases para una redefinición de la cultura, que se abrió a los márgenes de lo popular, abandonando la creencia de ser 
solo una cuestión de elite. Esta política militante deseaba un mundo globalizado, pero no advirtió el alcance de aquello que deseaba, pues, como comenta Giacché, no es la globalización soñada, sino la real la que se volvió una paradoja de la cultura, dejando vacíos en aquellos que fueron insertados y etiquetados en un espacio que no reconocían como propio. Eran los años de los s y de los totalitarismos. En este contexto:

El cine militante antes de la cinta de video y el teatro político antes de Darío Fo, practicaban poco y quizás mal, pero participaban incluso ellos en las muchas formas desordenadas e improvisadas de "hacer cultura" para todos, abriéndose a todas las culturas del mundo. La identidad del movimiento era absolutamente transnacional y los modelos y necesidades del otro estaban antes que el conocerse a sí mismo, debido a un enfoque en los otros que se descubría como una necesidad intelectual antes de presumirse como una opción moral. Finalmente o, sobre todo, la "palabra" - leer y escribir y decir - fue el medio de todos y el motor de todo, en esa babel diurna de asambleas, debates y documentos ... que precedió la larga noche de reuniones estratégicas y de discusiones tácticas que marcaron la transición a la estructura política y el abandono progresivo de las prácticas culturales y artísticas "superestructurales". Nada malo con esta maduración, excepto que cada vez que gana la política por sobre cultura, alguien realmente pone su mano en el arma ... Y, por ende, en la letra que borra "de golpe", incluso desde la memoria individual, esa mutación producida por el descubrimiento de la cultura minúscula y plural que estaba en cada lugar y en cada hombre Nuevo! (Giacché, 2013: en línea)

[Traducción libre de: Il cinema militante prima del videotape e il teatro politico prima di Dario Fo si praticarono poco e forse male, ma parteciparono anchessi dei molti disordinati e improvvisati modi di "fare cultura" per tutti, aprendosi a tutte le culture del mondo. L'identità del movimento era del resto immediatamente transnazionale e i modelli e i bisogni dell'altro venivano prima del conosci te stesso, per via di un'attenzione verso gli altri che si scopriva come una necessità intellettuale prima di vantarsi come un'opzione morale. Infine o prima di tutto, la "parola" - da leggere e da scrivere e da dire - era il mezzo di tutti e il motore di tutto, in quella babele diurna di assemblee e dibattiti e documenti... che ha preceduto la lunga notte di riunioni strategiche e di decisioni tattiche che segnarono il passaggio alla struttura politica e il progressivo abbandono delle pratiche culturali e artistiche "sovrastrutturali". Niente di male in questa maturazione, se non fosse che ogni volta che vince la politica sulla cultura, qualcuno mette davvero mano alla pistola... E quindi alla lettera cancella "di colpo", persino dalla memoria individuale, quella mutazione prodotta dalla scoperta della cultura minuscola e plurale che stava in ogni luogo e in ogni uomo. Nuovo!]

Es esta la gran diferencia con el nuevo enfoque de la tercera cultura que crea el teatro de exilio en sus negociaciones, pues, no pretende binarismos ni luchas, sino que concibe la política como un aspecto inherente a todo ser humano, como mera existencia y propiedad del Ser en lo social. No separa cultura de política; ambas son caras complementarias de un mismo fenómeno que pertenece a la humanidad. No pretende, tampoco, exaltar aquellas culturas con minúscula, pues, no concibe a ninguna cultura como mayúscula. Sin embargo, es importante poner en el horizonte cercano aquella advertencia que Giacché hace de la cultura como producto, mercancía, como bien cultural. Giacché expone una crítica profunda, casi una advertencia, sobre la cultura entendida hoy como un bien cultural:

"La cultura que, gracias a ellos, hoy se redefine una vez más, ya no es la que tiene una $C$ mayúscula, sino la de la $B$ de los bienes culturales. $Y$ después y detrás de ellos, un pequeño ejército de expertos y funcionarios, operadores y artistas que no 
hacen más que elaborar cuadros y didascalias, llenar vitrinas y organizar exposiciones, restaurar objetos y recuperar espacios, y finalmente fabricar performance y organizar festivales de todo aquello de cultural puede ser traducido en un "bien", acumulado en el "patrimonio", transformado en "inversión", mediante una política comercial y cultural que finalmente salvará la cultura y la patria juntas (...) La fiesta de la diversidad hace crecer la libertad, pero luego se agota en la igualdad, como no se quería demostrar." (en línea)

[Traducción libre de: "La cultura che - grazie a loro - oggi si ridefinisce ancora una volta, non è più quella con la $C$ maiuscola ma quella con la $B$ di beni culturali. $E$ dopo e dietro di loro, un piccolo esercito di esperti e funzionari, di operatori e di artisti non fanno che elaborare schede e didascalie, riempire teche e allestire mostre, restaurare oggetti e recuperare spazi e infine fabbricare performance e organizzare festival di tutto quello che di culturale può essere tradotto in "bene", accumulato nel "patrimonio", trasformato in "investimento", da parte di una politica cultural-commerciale che finalmente salverà insieme la cultura e la patria (...) La festa delle diversità fa crescere la libertà ma poi sfinisce nell'uguaglianza, come non volevasi dimostrare.]

En efecto, es delgada la línea que divide la cultura nueva que se quiere crear, producto de las negociaciones entre semejantes, y la cultura rentable que se aprovecha de aquellas minorias que pretende llamar a la negociación. El concepto fundamental es aquí el de negociación, pues, requiere un equilibrio ético al hecho de la creación conjunta de una nueva cultura teatral que no se impone como un ente moralista que necesita convencer al espectador, sino como un negociador de opiniones, experiencias, vivencias y puntos de vista divergentes. A menudo se olvida la ética por superar objetivos estéticos; sin embargo, desde la dimensión estética de Rancière, esto es imposible, pues la estética es entendida como un hacer y ser ético de la cultura y del arte.

Por ende, volviendo al Living Theatre, la revolución propuesta en un primer momento por el grupo en Estados Unidos se halla dentro de una concepción de cultura y política que dista de aquella experiencia de su exilio europeo, donde Malina, principalmente, reflexiona una "práctica más coherente de la utopía anarquista (en la vida teatral y comunitaria del grupo) y, al mismo tiempo, (...) la experimentación de métodos organizativos completamente nuevos" (Valenti, 2015: en línea) [Traducción libre de: "pratica più coerente dell'utopia anarchica (nel teatro e nella vita comunitaria del gruppo) e, contemporaneamente, dalla sperimentazione di modalità organizzative del tutto inedite."] Es la experiencia del exilio la que ha llevado al nuevo Living a una concepción renovada de cultura(s) y de política(s), permitiendo que la utopía cobre un sentido vital, plural y alterno, en pos de un teatro desplazado, ya no solo en lo físico y material (espacio teatral y elementos de la escena), sino, en su concepción radical de la existencia de otras realidades cambiantes que están siendo en el trayecto en devenir de la propia cotidianeidad.

Es esto lo que ha comprendido Czertok como política y cultura, pasando por su propio exilio y el de sus actores, viviendo este desplazamiento en carne propia y fragmentando su propia identidad teatral desde aquella utopía del aquíy ahora performativo. Porque este aquí y ahora se vuelve un cronotopo imposible cuando se desplaza en el bucle del encuentro con la diversidad incontenible de la(s) cultura(s) de la Nación, que se disemina dentro de cada creador mestizo.

Así, para Teatro Nucleo, el mayor riesgo que puede experimentar un teatrista se encuentra en la calle, donde se vive el verdadero malestar social, donde no puedes ocultar los procesos de montaje y donde el poder es compartido entre el espectador y el actor de manera idéntica e igualitaria. Es el lugar donde el espectador ve hasta que ya no tiene ganas y luego sigue su camino en total libertad. Pone a prueba a los actores, técnicos, músicos, dejándolos en lo que Czertok llama lugar adjunto (luogo 
deputato) y convirtiendo a los asistentes en espectadores. El espacio y sus circunstancias obligan a crear un lenguaje apto para poder comunicar, sin perder la complejidad del espectáculo ni la sutileza del arte. Es un espacio de riesgo por excelencia, desde la presencia de espectadores que no esperan presenciar un espectáculo, hasta el clima que siempre juega alguna mala pasada, todo es único y se constituye como un desafío. Este sacar fuera el teatro, corresponde al salir del marco en el cuadro del artista visual. Salir del marco es lo que permite explorar nuevos caminos, nuevas formas, materialidades, tiempos y contenidos y obliga a romper con las convenciones para investigar lo imposible.

El espacio es fundamental en la concepción teatral de Czertok. Éste ve en el espacio la posibilidad de expresar un nomadismo obligado, pero necesario, del ser humano y del creador, que no puede permanecer inmóvil en un lugar seguro, pues para encontrar las verdades es necesario estar siempre recorriendo diversos caminos y resistiendo a la hegemonía del poder. A su vez, experimenta con espacios fuera de las convenciones del edificio teatral mientras se encuentra en exilio. Esta selección de espacios exteriores responde claramente a una elección política que acerca el teatro al espectador y sale de su lugar seguro para obligar búsquedas de nuevos lenguajes más efectivos y afectivos.

Para Czertok, la plaza pública se vuelve un medio de resistencia frente a los nuevos medios de comunicación unidireccionales como la televisión o el internet, que no permiten una comunicación viva, en el sentido que le da Fischer-Lichte (2011), Dubatti (2005) y Dante (1994), un convivio como resistencia política a un lenguaje estandarizado y legitimado por el poder, una comunicación que haga bucles de interacciones entre espectadores y actores, cumpliéndose así, con la fiesta comunitaria. El teatro nace en los espacios públicos, luego se realiza en plazas y calles, para ser después escondido, por considerarse peligroso, en edificios seguros y cómodos, fomentando, en parte, el estancamiento de sus formas. Es por ello que el teatro debe salir y ver-ser el mundo.

La elección de la plaza pública corresponde también a un objetivo social, pues es la plaza el centro de reunión ciudadana desde tiempos inmemorables, "Un público es en primer lugar una reunión." (Sartre, 1979: 71). Es allí donde se encuentra al espectador distraído que no sabe aún que debe representar su rol, encarnar su papel, ser autor y creador del espectáculo que está viniendo a encontrarlo. No se debe olvidar que el espectador es el eje de la actividad estética, pues "El primer momento de la actividad estética es la vivencia: yo he de vivir (ver y conocer) aquello que está viviendo el otro, he de ponerme en su sitio, como si coincidiera con él." (Bajtin y Voloshinov, 1992: 30) O como dice Vajtangov: “(...) el teatro no es para el pueblo. El teatro se hace con el pueblo. (...) el arte ha de ir al encuentro del alma del pueblo. El alma del pueblo, tras el encuentro con el alma del artista, ha de producir una creación auténticamente popular (tal vez un mito). Los anhelos artísticos han de arrancar del pecho del pueblo el lenguaje que en él se ha forjado." (1997: 189, 190). 


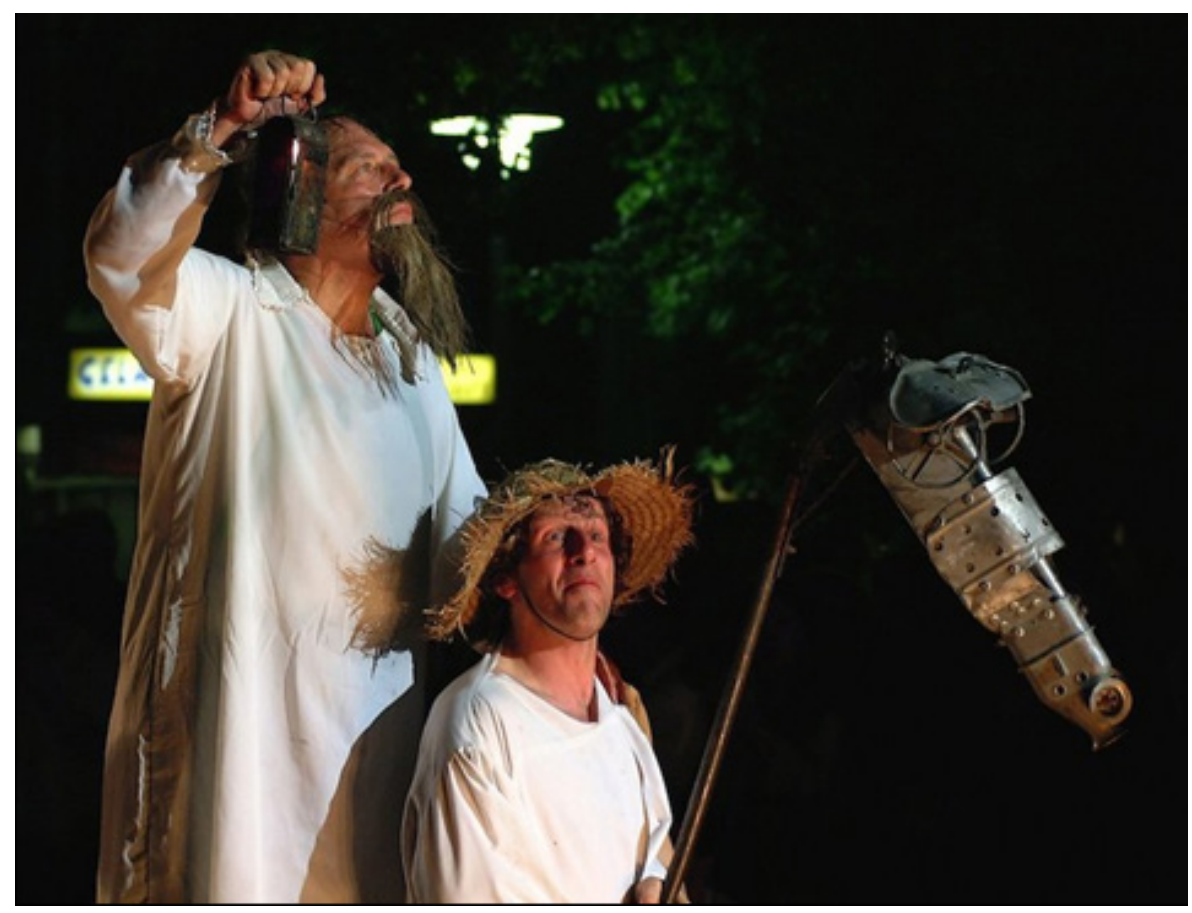

Teatro Nucleo en Quijote (1990). En la fotografía: Horacio Czertok y Christophe Cardoen. - Fuente: http://www.teatronucleo.org/

Czertok también considera un hecho político este salir a entregar teatro a todos los ciudadanos que, de alguna manera, se han marginado del teatro, pues el pago de las subvenciones que la comunidad otorga al teatro, aunque sea el Estado quien las concede, proviene de los impuestos que pagan estos mismos ciudadanos. Este factor económico los impulsa a escoger espacios públicos, pues, solo así, todos tienen la posibilidad de ver el espectáculo que, conscientes o no, han pagado. "También hay una clara respuesta política al uso del teatro en espacios abiertos como una lucha contra la barbarie de las relaciones, contra la cultura de la muerte, por un aumento en la calidad de vida." (Czertok, 2010: 226)[ [Traducción libre de: "C’è inoltre un evidente riscontro político nell'utilizzo del teatro negli spazi aperti anche come lotta contro limbarbarimento dei rapporti, contro la cultura della norte, per un innalzamento della qualità della vita."] Convirtiendo, a su vez, a los actores y grupos teatrales en verdaderos embajadores del teatro.

\section{El método del laboratorio teatral de Czertok}

En su libro "Teatro de exilio" (1999), Horacio Czertok analiza el trabajo de laboratorio que ha llevado a cabo desde la fundación de Teatro Nucleo. Al respecto expone:

¿Qué es el Teatro Nucleo? Un laboratorio teatral. No es una habitación embaldosada: es una forma de estar en el mundo, de vivir las relaciones consigo mismo y con los demás. Es una escena que se ve en la calle, es trabajar por horas en un gesto, es la forma en que tomas un café en el bar. Si el teatro es una síntesis de la vida, no podemos circunscribir la investigación y la experimentación dentro de ninguna frontera. Como el universo es el laboratorio del poeta. (Czertok, 2010: 83)

[Traducción libre de: “Cosè il Teatro Nucleo? Un laboratorio teatrale. Non una stanza piastrellata: è un modo di stare nel mondo, di vivere le relazioni con se stessi e con gli 
altri. Ė una scena vista sulla strada, è lavorare per ore su un gesto, è il modo in cui prendi un caffe al bar. Se il teatro è sintesi di vita, non possiamo circoscriverne la ricerca e la sperimentazione entro nessun a frontera. Come l'universo è il laboratorio del poeta."]

Esta concepción de laboratorio teatral como una migración constante en la búsqueda de nuevas formas de expresión y creación nos presenta un tipo de trabajo rizomático, que permite al actor-investigador realizar las infinitas conexiones que son necesarias para una forma teatral nómade. Teatro Nucleo no solo realiza su laboratorio investigando en diversos lugares y con múltiples referentes disciplinares (que mete en cuestión en su práctica, sino que extiende las fronteras del mismo espectáculo hacia países y ciudades diversas, cuestionando el concepto de tiempo y espacio teatral que resulta ser, en esta modalidad, un periplo creativo que enriquece la escena y la performance de sus actores.

Czertok ha descubierto que existe un concepto base para desarrollar el trabajo de investigación teatral: la técnica. Para el creador, la técnica implica un aprender a relacionarse con el propio cuerpo-psique desde una desprogramación de la técnica misma que hemos utilizado por siglos y que es idéntica a la que usamos con las máquinas de nuestra vida cotidiana, es decir, la técnica no puede permanecer fija, debe moverse, mutar, dependiendo de quién la aplique y de los propios impulsos. Una técnica estática, que fija formas y contenidos es nada más que un manual de instrucciones que caduca constantemente en relación con un cuerpo vivo. Por ello, Czertok concibe la técnica como un nuevo camino en desplazamiento, citando al poeta Machado "se hace camino al andar" (Czertok, 2010: 83). Advierte, a su vez, que no es posible pensar ingenuamente que la técnica puede prescindir de quien la aplica, que no existen técnicas neutras, pues éstas serían más bien un mecanismo de autodefensa; que una herramienta para sacar de dentro del actor aquello que se suele mantener oculto. Para evitar esta neutralización de la técnica, Czertok propone tener siempre presente la experiencia de cada participante del laboratorio, sujeto y guía que resultan ser los mismos durante la búsqueda, una experiencia compartida, sin que haya uno más importante que otro. El guía será el que haya recorrido más veces el camino y sepa de sus características y peligros, pero el viaje, dice Czertok, se hace juntos, por ello, siempre el camino será nuevo. (2010: 83)

El trabajo teatral requiere una apertura y una disposición al hecho de que, en el arte, la fantasía, la imaginación y la intuición tienen primacía sobre la Ratio, en el sentido cartesiano del término. La cultura nos ha condicionado a ser guiados mayormente por la actividad del hemisferio izquierdo del cerebro, el que preside la racionalidad, y a no confiar en ciertas señales de estímulos provenientes del hemisferio derecho, que gobierna la subjetividad. Asignamos valor a ciertos estímulos e ignoramos otros mediante inhibiciones: por ejemplo, tendemos a despreciar la intuición porque es subjetiva y no mensurable. Por lo tanto, en nuestro cuerpo hay un choque continuo entre los sentimientos resultantes de esos estímulos y señales, intuiciones e inhibiciones. Si uno quiere entrar en el arte y actuar a través de él, primero es necesario aceptar y comprender la existencia de este conflicto, y para hacerlo, uno debe aceptar modificar el propio sistema de valores. Una verdadera transformación cultural. (Czertok, 2010: 84)

[Traducción libre de: "Il laboro teatrale esige un'aperturae una disponibilità al fatto che, nell'arte, la fantasia, l'immaginazione e l'intuizione hanno il primato sulla Ratio, nel senso cartesiano del termine. La cultura ci ha condizionato ad essere pilotati maggiormente dall'attività dell'emisfero sinistro del cervello, quello che presiede alla razionalità, e a non fidarci di certi stimolie segnali che provengono dall'emisfero destro, che governa la soggettività. Assegniamo valore a determinati stimoli e ne disconosciamo altri attraverso le inibizioni: per esempio tendiamo a disprezzare l'intuizione perché 
soggettiva e non misurabile. Perciò nel nostro corpo ha luogo uno scontro continuo tra i sentimenti conseguenti a quegli stimoli e segnali, le intuizioni e le inibizioni. Se si vuole entrare nell'arte ed agire per il suo tramite, prima di ogni cosa è necessario accettare e comprendere l'esistenza di questo conflitto, e per poterlo fare bisogna accettare di modificare il proprio sistema di valori. Una vera e propria trasformazione culturale."]

La Ratio (razón) es el pilar fundamental de la filosofía cartesiana, pues para Descartes, todos los conocimientos y todas las verdades universales (de las cuales se desprenden las ciencias) nacen de la razón. Para Czertok, el uso de un solo lado del cerebro en el aprender y conocer, limita al ser humano y lo fragmenta, provocando que el cuerpo-psique se halle en constante conflicto y, por ende, en permanente tensión. Desconociendo el lado izquierdo del cerebro, dejamos también de conocer aquellas verdades universales que no pueden ser medidas. Este paradigma de la ratio nos ha conducido a fijarlo todo, a obsesionarnos con las estructuras que nos dicen qué y cómo debemos ver, conocer y aprender el mundo. Estructuras que tienden a definir, y con ello, se entiende generalmente, fijar conocimientos. La experiencia ha demostrado que es posible (y absolutamente más enriquecedor) plantear definiciones desterritorializantes, que puedan moverse y crear estructuras rizomáticas, verdaderas cartografías en el sentido que ha sido señalado por Deleuze-Guattari, lo que permite una flexibilidad y una red viva de conocimientos que no terminan jamás. Es esta la transformación cultural de la que habla Czertok en su propuesta de laboratorio teatral, de técnica y del actor guía. En este sentido, su teatro de exilio nos vuelve a corroborar que es fundamental cambiar la óptica de las relaciones teatrales, dentro y fuera de escena, asumiendo que no es posible referirse a una teatralidad, si no, más bien, a teatralidades en movimiento.

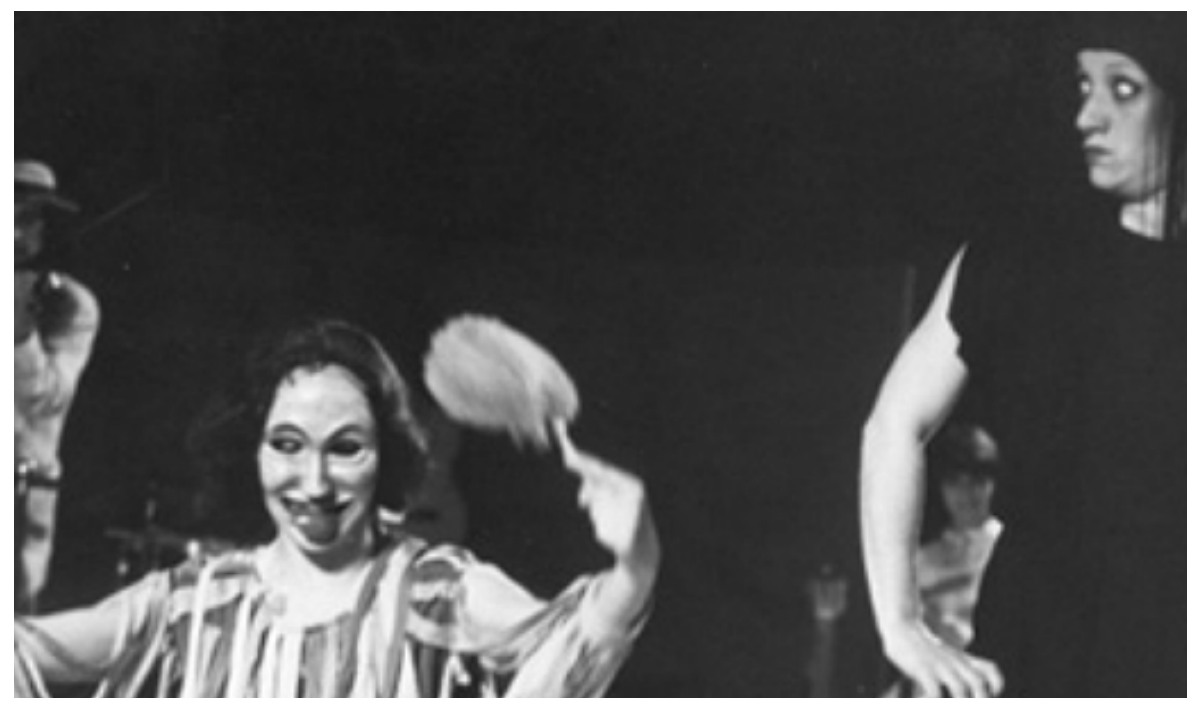

Eresia (1980) de Teatro Nucleo. - Fuente: http://www.teatronucleo.org/

El concepto de exilio en el Teatro Nucleo está presente en cada una de las etapas del trabajo de Czertok, ampliando su sentido político como un componente inherente al actor transcultural y transdisciplinar. Su concepción de laboratorio se centra en una investigación constante teórico-práctica y que admite el error como un componente necesario para el descubrimiento de formas nuevas. Trabaja con actores profesionales que se nutren de experiencias compartidas, para luego volcarlas escénicamente y pedagógicamente con jóvenes que inician su recorrido en los laboratorios didácticos que Teatro Nucleo ofrece a la comunidad. Dentro del laboratorio, el juego es fundamental, pues es el medio por el cual el actor permite a su inconsciente liberar la 
curiosidad inherente al ser humano y que con los años se oculta convenientemente. En el juego, Czertok introduce los principios del método Stanislavski y luego desafía sus principios para entrar y salir de las reglas escénicas y prepararlo para el complejo espacio teatral que afrontará: la ciudad.

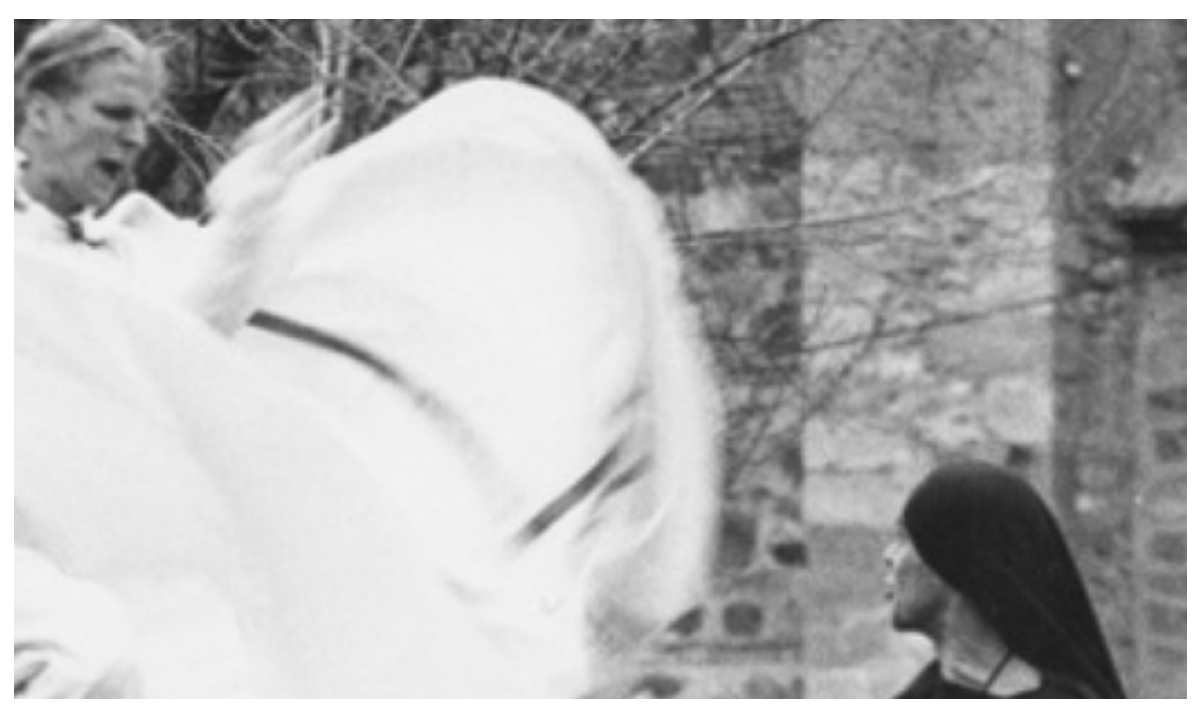

Luci (1980) Teatro Nucleo. - Fuente: http://www.teatronucleo.org/

\section{La ciudad como escenografía: somos inmigrantes y exiliados}

En una entrevista que le realicé durante el verano de 2017 (b) en el teatro Julio Cortazar de Ferrara, a Horacio Czertok comentó que la mejor escenografía que había visto en su vida se hallaba en las calles de las ciudades. Los edificios, las fuentes de agua, los árboles, los monumentos eran el marco perfecto que penetraba las obras y a los actores y éstos se llenaban de la belleza del entorno en una relación de encuentro reciproco que era compartido por el espectador distraído, improvisado y pasajero, siempre tomando fragmentos del espectáculo y llevándolos consigo en su trayecto. Czertok había encontrado la magia del espacio público y había descubierto todas las posibilidades sociales, artísticas y políticas que éste ofrece.

En su libro comenta que hacer teatro de calle no había sido una elección; más bien, la única opción para un grupo de inmigrantes y exiliados que, al establecerse en un nuevo país, dejaban de ser seres exóticos con espectáculos exóticos: "Tan pronto como les hicimos saber que habíamos decidido quedarnos, no regresar a Argentina, sucedió, pero de hecho lo entendimos muchos años después, que nos convertimos de exóticos en competidores. Es natural: todos intentan defender su entorno de la competencia." (Czertok, 2010: 79) [Traducción libre de: "Non appena facemmo sapere che avevamo deciso di rimanere, di non tornare più in Argentina, accadde, ma questo lo capimmo in realtà molti anni dopo, che da esotici diventammo concorrenti. È naturale: ciascuno cerca di difendere il proprio ambiente dalla concorrenza."]

Así, la única opción fuera del sistema teatral que se cerraba a la competencia, eran las plazas, las calles, los mercados, las ferias, espacios que pertenecían a los saltimbanquis sin pedigrí teatral. Los actores quedaban de modo convertidos en juglares del teatro y no en actores de escenario y sala. Para Czertok, esta era la situación que mejor los definía como grupo teatral, ya que se consideraban ciudadanos del mundo como inmigrantes y fuera de toda asociación corporativa como exiliados. La errancia 
era el signo que los identificaba como expulsados de todo territorio reconocido y fijo y las calles eran justamente el espacio donde podrían construir una nueva y errante identidad.

Desafortunadamente, las actuaciones callejeras a menudo se hacen sin competencia o calidad. Como si los actores de la calle asumieran un orden tácito del sistema teatral: ser actores de segunda clase. Ninguna o mala preparación técnica: cuerpos descuidados, gestos obvios, voces vacías, miradas planas, relaciones con herramientas triviales y predecibles, relaciones entre actores inexistentes, relaciones con el espectador marcadas por la superficialidad. Escasa competencia de los directores: drama inexistente o predecible, ausencia de personajes valiosos, producciones mediocres, situaciones que se resuelven con abuso de efectos que son un fin en sí mismos. La lección de generaciones enteras de gente de teatro parece perdida aquí: es cierto que incluso en los teatros "verdaderos" resulta difícil encontrarla, pero también es cierto que en la calle esta ausencia es aún más deplorable, porque aquí es incluso más necesaria. (Czertok, 2010: 79-80)

[Traducción libre de: Sfortunatamente troppo spesso gli spettacoli di strada sono fatti senza competenza né qualità. Come se gli attori di strada assumessero un ordine tacito del sistema teatrale: l'essere attori di seconda classe. Nessuna o scarsa preparazione tecnica: corpi sciatti, gesti ovvi, voci vuote, sguardi piatti, rapporti con gli attrezzi banali e prevedibili, relazioni tra attori inesistenti, relazioni con lo spettatore improntate alla superficialità. scarsa competenza nei registi: drammaturgie inesistenti o prevedibili, assenza di personaggi degni, allestimenti mediocri, situazioni che si risolvono con abuso di effetti fine a se stessi. La lezione di intere generazioni di persone di teatro sembra qui smarrita: è vero che anche nei teatri "veri" la si ritrova a fatica, ma è anche vero che sulla strada questa assenza è ancora più deprecabile, perché qui è ancora più necessaria."]

Si bien lo que declara Czertok se cumple aun en nuestros días, es fundamental destacar que el teatro de calle ha tenido varios e importantes exponentes que escapan a estas características que se le suelen atribuir, un ejemplo de ello es el Living Theatre -compañía creada en 1947 en New York por Julian Beck y Judith Malina- que le otorga a este tipo de teatro (denominado así por su espacio) un valor ideológico, al rechazar los recintos teatrales convencionales para ir en busca de los espectadores que no suelen ir al teatro. Sabemos que el Living Theatre utilizó la provocación (asociada al agit-prop) para remecer a los espectadores habituados a estar sentados cómodamente en sus butacas. Para Beck y Malina, el teatro debía ser una herramienta de transformación social; por ende, poseían un fuerte componente político. Al salir de los espacios convencionales, se estaba también saliendo del sistema que estaba al servicio del poder y de una clase dominante. Los actores del Living comenzaron a realizar creación colectiva y a involucrarse activamente en conflictos políticos y sociales. Para Beck, los espectadores debían participar de las obras para vivir la experiencia y poder reflexionar sobre los contextos sociales que estaban necesitando urgente atención. Así, sus obras estimulaban todos los sentidos y, con ello, todas las conciencias. Los temas recurrentes eran las luchas sociales contra el racismo, las invasiones militares, la equidad sexual, la libertad de expresión, entre otros.

Un grupo de personas se reúne. No hay autor para apoyarse en él, que te arrebate el impulso creador. Destrucción de la superestructura de la mente. Entonces aparece la realidad. Nos sentamos juntos durante meses hablando, absorbiendo, creando una atmósfera en la que no sólo nos inspiramos mutuamente, sino que además cada cual se siente con toda libertad para decir lo que le apetezca. Enorme jungla pantanosa, un paisaje de conceptos, almas, sonidos, movimientos, teorías, helechos de poesía, tosquedad, páramos, vagabundeos. Luego se une y toma forma. En 
el proceso se presenta una forma. La persona que menos habla puede ser quién inspira a la que más habla. Al final nadie sabe quién era realmente responsable de lo obtenido, el ego individual desaparece en la oscuridad, todos están contentos, todos tienen una satisfacción personal mayor que la de quién está solo. Una vez que se ha sentido esto, el proceso de la creación artística en colectivo, volver al viejo orden parece una regresión. La creación colectiva es un ejemplo del Proceso Autogestivo Anarco-Comunista que tiene más valor para el pueblo que una obra de teatro. La creación colectiva como arma secreta del pueblo. (Beck, 1974: 102)

Luego de una brutal persecución en su país, el Living decidió emigrar a Europa (1964), donde fueron perseguidos por sus espectáculos de agitación política y social, participando en las protestas francesas de Mayo del 68, mientras que, como invitados en el Festival de Avignon, renunciaron a ser parte de la programación cuando la organización les pidió que cambiaran la obra y dejaran de representar Paradise Now en las calles de la ciudad. Luego pasaron dos meses en prisión en Brasil, país que visitaron mientras estaba en dictadura. Al regresar a los Estados Unidos, continuaron siendo agredidos por la prensa, que los consideraba un peligro para la sociedad norteamericana. Su teatro de calle fue un ejemplo que siguieron numerosas compañías de teatro en todo el mundo y de la que nacieron otras propuestas de impecable calidad actoral y espectacular. Es a este teatro de calle que apunta Czertok cuando inicia su investigación en Italia, un teatro provocador que despierte conciencias y que no esté libre de los siete mandatos del teatro contemporáneo que declara Beck:

Los Siete Mandatos del Teatro Contemporáneo:

1. En la Calle: fuera de las limitaciones culturales y económicas del teatro institucionalizado.

2. Gratuito: Representaciones para el proletariado, los pobres, sin cobrar entradas.

3. Participación Abierta: Romper las barreras. Unificación: Creación Colectiva.

4. Creación Espontánea: Improvisación: Libertad.

5. Vida Física: Cuerpo: Liberación Sexual.

6. Cambio: Crecimiento de la Atención Consciente: Revolución Permanente: Ideología Abierta (Flexible, Libre).

7. Actuación como Acción. (Beck, 1974: 86-87)

Como Beck y Malina, Czertok conocía perfectamente el exilio y sus implicancias. También comprendía el teatro como herramienta de cambio social y político. Sentía la urgencia de agitar las conciencias del mundo frente a las injusticias que se vivían en el continente que lo vio nacer. Por ello, su primer espectáculo de revuelo fue Herodes, una obra de violencia descarnada que plasmó el propio testimonio de Czertok de su tortura, quedando, en la memoria de quienes la vieron, como una impactante denuncia de los crímenes de la dictadura argentina. 


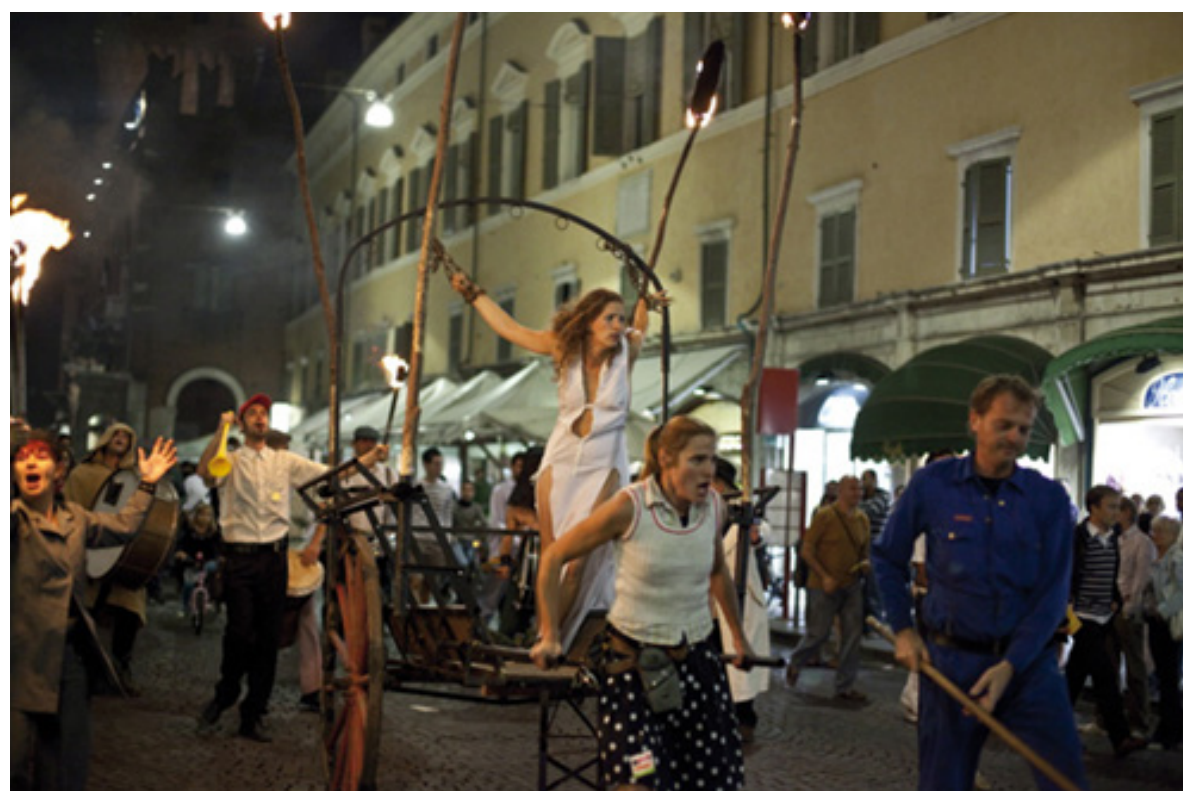

Orlando Furioso parte del proyecto internacional Mir Caravan (2010). Fuente: http://www.teatronucleo.org/

La calle, la plaza, en fin, el espacio abierto, presentó grandes desafíos para Teatro Nucleo, pues ninguna academia prepara a los actores para afrontar técnicamente los problemas que allí surgen. Fuera de la protección que ofrece la sala de teatro, no hay ninguna certeza. Fuera del edificio teatral no existe el espectador profesional (término utilizado por Czertok); por ende, los actores de Teatro Nucleo deben plantearse dos tareas fundamentales: representar a la perfección sus personajes y atraer y mantener la atención del espectador transeúnte. A este desafío se suma la multiplicidad de lenguas de los espectadores transeúntes: por las calles europeas transitan personas de diversas nacionalidades y culturas. Otro factor es la voz, que debe ser manejada de manera diversa, ya que no hay muros diseñados para ayudar al actor en su proyección. Los ruidos de la calle no cesarán en favor del espectáculo. La diversidad etaria de los espectadores es otro factor a considerar, como sí también las mascotas y niños pequeños, habitualmente no son permitidos en los teatros tradicionales, pero que no pueden ser marginados del espacio que les pertenece. Son los actores; es el espectáculo el que invade un espacio distinto, como un inmigrante o un exiliado llega a un país que no conoce y aun así debe vivir. Y podemos agregar a esta lista, el clima, éste se transforma, como en los insipientes teatros primitivos, en la guía para continuar o suspender la función.

Así, Czertok descubre la importancia del concepto hecho carne: el grupo teatral. El grupo es, en palabras de Czertok (2010: 45): “(...) aquello que más nos restituía dignidad."[Traducción libre de: "(...) quello che più ci restituiva dignità."] Pues les permitía ser vistos como inmigrantes y no como exiliados. Este rechazo a la condición de exiliado se debe a las miradas caritativas y lastimeras que sufrían a menudo. La dignidad se presentaba en el trabajo colectivo de un grupo de personas unidas, solidarias y con un objetivo común: vivir del teatro y no de la caridad. El grupo teatral se mantenía por sí mismo, realizando todas las tareas que tradicionalmente realizan otros profesionales como maquilladores, técnicos, tramoyas, iluminadores, sonidistas. El grupo lo contiene todo; todos son trabajadores del teatro al servicio del teatro. A su vez, el grupo permite a los actores desarrollar la creatividad necesaria para la creación que no puede darse en ambientes controlados por reglas rígidas. Al respecto, Czertok cita algunos ejemplos que le sirvieron para sustentar esta elección: 
El teatro de arte de Stanislavski era una parte importante del establishment, pero cuando quiso profundizar sus estudios, encargó a su asistente Sulerszisky organizar a los actores en un grupo y llevarlo al campo, fuera de los ritmos productivos y las distracciones de la metrópoli. Grupo fue el Teatr Laboratorium de Grotowski, grupo fue el Cricot de Kantor, grupo es el Odin Teatret. Grupo era y es el Living. (Czertok, 2010: 46-47)

[Traducción libre de: “Il Teatro d'arte di Stanislavskij era parte importante dell'establishment, ma quando volle approfondire gli studi incarico il suo assistente Sulerszisky di organizzare gli attori in gruppo e portarlo in campagna, fuori dai ritmi produttivi e le distrazioni della metropoli. Gruppo fu il Teatr Laboratorium di Grotowski, gruppo era il Cricot di Kantor, gruppo è l'Odin Teatret. Gruppo era ed è il Living."]

A partir de estos ejemplos, Teatro Nucleo tuvo claro desde el inicio de su exilio, que debía encerrarse a crear para luego abrirse a los espectadores de las calles, a los espacios también abiertos, enfrentando cada desafío como grupo, apreciando sus diferencias y un estado compartido que los marcaba: el exilio, la inmigración. Tanto Horacio como Cora han trabajado juntos desde Buenos Aires, en Comuna Baires, hasta Ferrara con Teatro Nucleo, colaborando con diversas compañías del mundo y elaborando proyectos de teatro social con pacientes psiquiátricos, reclusos de las cárceles, refugiados políticos. El trabajo social de Teatro Nucleo es para y no con estos pacientes o reclusos. En sus obras no incorporan a estos actores; sino más bien, crean espectáculos y laboratorios para ellos.

\section{Conclusiones}

Partiendo por los significados que conforman el concepto de exilio, que posee una larga y vasta historia como castigo impuesto a los individuos considerados una amenaza al poder imperante, es posible distinguir algunas características comunes: la fragmentación, la desestabilización y alienación identitaria que éste provoca en el ser humano. El exiliado es aquel individuo que se halla en un territorio en tránsito imposible de estabilizar, pues, aunque logre el retorno a la tierra anhelada, ésta no será nunca aquel lugar que se vio forzado a abandonar. Por ello, el exiliado es un ser liminal, que se encontrará transitando entre el aquí y allá perpetuamente.

Los artistas exiliados de todas las épocas, en un intento por estabilizar su identidad particular y colectiva, han encontrado diversas estrategias creativas para configurar territorios conocidos y cercanos en donde habitar la diferencia y volverse entes radicantes por excelencia. El exilio es una lucha constante por pertenecer, ya sea en el aquí o en el allá; por ello, el teatro se configura como un territorio común donde la diferencia y la fragmentación identitaria cobran valor vital en el espacio de la différan$c e$, aquel diferir, desplazar el significado hacia un futuro móvil y por ello, incierto. Al desplazar el significado en un continuo movimiento, éste se vuelve rizomático, abierto e inconcluso. El origen se ha perdido o transformado, convirtiéndose en memoria desplazada. La memoria, por lo tanto es un movimiento no lineal que viaja en las diversas dimensiones del tiempo-espacio, en donde el significante queda revoloteando como huella material de la materialidad que fue y que lo compuso.

En este panorama, una parte importante del teatro ha asumido la memoria desplazada en sus formas, recorriendo un largo trayecto hacia la hibridación disciplinaria, acercándose a la performance hasta hacerla parte de su actual configuración. Así, el teatro y la representación (propia de este topos) se han agrietado para dejar entrar la presentación performativa. Horacio Czertok ha sido uno de los primeros latinoamericanos en crear puentes entre ambas disciplinas, construyendo un teatro performance 
latinoamericano de exilio en los intersticios de la fractura, mostrando la herida que provoca el exilio en el ser humano y en la expresión escénica, pues, el exilio como la performance, desestabiliza las fronteras identitarias del ser humano y del teatro. Pero también, mostrando que, por medio del aspecto terapéutico del teatro, es posible crear sin dolor y transmitir al espectador que la vida siempre se abre camino.

Teatro Nucleo propone una expresión atravesada por los significados del exilio sin declaralo de manera frontal: transdisciplinariedad, transculturalidad, hibridación. Y aclaro que el prefijo trans exhorta los cruces de sentidos que van a devenir un territorio Otro de creación, un tercer espacio, como analiza Fernando De Toro, en donde se negocia la alteridad de los sujetos participantes del hecho teatral. Para Czertok, el actor habita en el puente, no sale de él y el espectador lo acompaña con la sensibilidad y la inteligencia de sus emociones al presenciar/experimentar la herida descarnada, rebelándose a los cánones impuestos por la tradición y la jerarquía, tanto social como teatral, por medio de la mirada atenta de las configuraciones sígnicas de la escena.

Otra característica relevante del Teatro Nucleo es su metodología de trabajo con el actor. Ésta se construye por medio de múltiples hibridaciones de métodos y referentes diversos que se transforman en huellas dactilares de los actores, pues se adecuan a las necesidades personales de cada uno. Todo ello, dentro del trabajo de laboratorio teatral, concebido como espacio de enseñanza y reflexión práctica y teórica, como espacio de creación e intercambio, dejando al actor proponer escenas y diálogos para los espectáculos. Su training se centra en sacar del actor aquello que no suele mostrar en su cotidianidad, para que desde ahí comience a convertir el sentimiento en imágenes creadoras de realidades. Czertok utiliza el espacio público como fractura a la institucionalidad y como medio de llegar con el teatro al espectador improvisado, aquel que deambula por las calles o plazas sin saber que se convertirá en espectador. Para el creador, este aspecto constituye un actuar político, una rebelión frente a las jerarquías que imponen las salas teatrales convencionales. El espacio es comprendido como lugar de y para la terapia del actor y del espectador, pues, simboliza el desplazamiento del artista hacia el lugar extrañado, la plaza que deviene escenario. El espectador deviene soldado del arte al estar frente al espectáculo extrañado, decodificando los signos escénicos para purgar los males sociales y humanos. Czertok concibe la relación espectador-actor como un campo de batalla en donde se deben utilizar tácticas de guerra para convertirlo en parte de un nuevo ser humano, que no permanezca en silencio frente a las injusticias y atrocidades del mundo. Así, propone el exilio como medio para desestabilizar al actor y al espectador, poniéndolos en igualdad de condiciones. Los signos del exilio los incorpora en las materialidades de la escena: las máquinas, el fuego, las voces traficadas por micrófonos, grabaciones, los cuerpos violentos en medio de un contexto violento. A su vez, el exilio se muestra en la fractura que ejerce a los textos dramáticos canónicos que sirven de inspiración para sus espectáculos. Czertok trabaja con el método Stanislavski que organiza en una curva dramática aplicada a la actuación teatral, la quiebra con la improvisación performativa, por medio de la incorporación de sus propias vivencias y sentimientos en la interpretación del personaje. Por este medio, asume el exilio como posibilidad creadora y como una herida que solo puede sanar por medio del aspecto terapéutico del teatro. 


\section{Dibliografía}

» Alighieri, D. (1994). “El Convite.” En: González Ruíz, N. y Gutiérrez García, J. L. (Trad. Y Colab.), Obras completas de Dante Alighieri. (pp. 565-691). Madrid: Biblioteca de Autores Cristianos

" Artaud, A. (1971). El teatro y su doble. París: Gallimard

»Bajtín, M., Voloshinov, V. (1992). El marxismo y la filosofía del lenguaje. Madrid: Alianza

» Beck, J. (1974). El Living Theatre. Madrid: Ediciones Fundamentos

"Bhabha, H. (1994/2002). El lugar de la cultura. Buenos Aires: Manantial

"Czertok, H. (1985). Teatro Nucleo. Cenni storici e ontologici. Manuscrito inédito archivo del Teatro Nucleo.

»Czertok, H. (2010). Teatro In Esilio. Appunti e riflessioni sul lavoro del Teatro Nucleo. ( $3^{\circ}$ ed.). Ferrara: Ediciones Teatro Nucleo.

»Czertok, H. (2017). “Entrevista de Claudia Cattaneo a Horacio Czertok.” Archivo personal de la investigadora. Realizada en agosto de 2017 a las 11:30 A.M., en el Teatro Julio Cortazar. Ferrara: Ponte Largoscuro.

»Czertok, H. (s.f.). “Sitio oficial de Teatro Nucleo." [en línea]. Consultado el 17 de marzo de 2017 en http://www.teatronucleo.org/tag/horacio-czertok/

»Dubatti, J. (2005). “Cultura teatral y convivio”. Revista Conjunto abril-junio (136) 88-96 La Habana: Casa de las Américas

»Dubatti, J. (2006). El convivio teatral: Teoría y práctica del teatro contemporáneo. Buenos Aires: Editorial EOL

"Etchegaray, R. (2014). “La filosofía de Jacques Rancière." Nuevo Pensamiento. Revista de Filosofía del Instituto de Investigaciones Filosóficas de la Facultad de Filosofía de la Universidad del Salvador, 4 (IV) [en línea]. Consultado el 18 de diciembre de 2017 en http://mabs.com.ar/nuevopensamiento/index.php/ nuevopensamiento/index

" Famá Hernández, R. (2012). “Comuna Baires: De la utopía al exilio (1969-1974)”. Colecciones teatrales, [en línea]. Consultado el 26 de marzo de 2019 en www. coleccionesteatrales.blogspot.com

» Fischer-Lichte, E. (2011). Estética de lo performativo. Madrid: Abada Editores

» Giacchè, P. (2013). "La cultura e la política." En Sinistra in rete, Lo straniero. Arte-cultura-scienza-società. [en línea]. Consultado el 23 de marzo de 2019 en https://www.sinistrainrete.info/cultura/2615-piergiorgio-giacche-la-cultura-ela-politica.html

»Peloso, P. (2017, o8 de julio). "Teatro e deistituzionalizzazione. Intervista con Horacio Czertok (Parte I)." [en línea]. Consultado el 16 de mayo de 2018 en http://www.psychiatryonline.it/node/6859

» Rancière, J. (1996/2007). El desacuerdo. Política y filosofía. Buenos Aires: Nueva Visión

"Said, E. (2013). Orientalismo. Barcelona: Debolsillo

» Sartre, J. P. (1979). Un teatro de situaciones. Saura, J. (ed.). Buenos Aires: Losada. 
» Taylor, D. (2014). "El espectáculo de la memoria: trauma, performance y política." Performancelogía. Todo sobre arte de performance y performancistas. [en línea]. Consultado el 12 de julio de 2020 en http://performancelogia.blogspot. com/2007/o8/el-espectculo-de-la-memoria-trauma.html

"Todorov, T. (1993). La memoria amenazada. Biblioteca Virtual de Ciencias Sociales [en línea]. Consultado el 24 de junio de 2020 en www.cholonautas.edu.pe

"Vajtangov, E. (1997). Teoría y práctica teatral. Madrid: Asociación de directores de escena de España

"Valenti, C. (2015, 13 de abril). "Judith Malina, la più radicale e profonda rivoluzionaria del teatro." Revista digital Ateatro. Webzine di cultura teatrale, (154). [en línea]. Consultado el 26 de marzo de 2019 en http://www.ateatro.it/webzine/2015/04/13/judith-malina-la-piu-radicale-e-profonda-rivoluzionaria-delteatro/ 